\title{
Dinâmica da serapilheira em pastagens de braquiária em sistema silvipastoril e monocultura
}

\author{
Deise Ferreira Xavier(1), Francisco José da Silva Lédo(1), Domingos Sávio de Campos Paciullo(1), \\ Maria de Fátima Ávila Pires ${ }^{(1)}$ e Robert Michael Boddey(2)
}

\begin{abstract}
(1)Embrapa Gado de Leite, Rua Eugênio do Nascimento, № 610, CEP 36038-330 Juiz de Fora, MG. E-mail: dfxavier@cnpgl.embrapa.br, ledo@cnpgl.embrapa.br, domingos@cnpgl.embrapa.br, fatinha@cnpgl.embrapa.br ${ }^{(2)}$ Embrapa Agrobiologia, Caixa Postal 74.505, CEP 23890-000 Seropédica, RJ. E-mail: bob@cnpab.embrapa.br
\end{abstract}

Resumo - O objetivo deste trabalho foi avaliar o efeito da introdução de leguminosas arbóreas e eucalipto em pastagens de braquiária (Urochloa decumbens cv. Basilisk), na dinâmica da serapilheira. O estudo foi realizado em sistema silvipastoril e em monocultura, em 12 meses. O delineamento experimental foi o de blocos ao acaso, com seis repetições e cinco animais por piquete. Foram avaliadas a serapilheira existente e a depositada. A serapilheira existente teve média anual de 5.038 e $3.944 \mathrm{~kg} \mathrm{ha}^{-1}$, no sistema silvipastoril e na monocultura, respectivamente. $\mathrm{O}$ sistema silvipastoril causou um acréscimo significativo na serapilheira depositada. A quantidade de nitrogênio da serapilheira depositada foi maior no sistema silvipastoril, do que na monocultura, respectivamente, $228 \mathrm{~kg} \mathrm{ha}^{-1}$ por ano e $107 \mathrm{~kg} \mathrm{ha}^{-1}$ por ano. A presença de leguminosas e de eucalipto em sistema silvipastoril proporcionou aumentos nas quantidades de nitrogênio, comprovados pela análise isotópica de ${ }^{13} \mathrm{C}$, e matéria seca de serapilheira. Incrementos na produção de serapilheira rica em nitrogênio pode contribuir para a sustentabilidade das pastagens de braquiária a longo prazo.

Termos para indexação: Brachiaria decumbens, Urochloa decumbens, fluxo de nitrogênio, leguminosas arbóreas, pastagens tropicais.

\section{Litter dynamics in signal grass pastures in a silvipasture system and in monoculture}

\begin{abstract}
The objective of this work was to evaluate the effect of legume trees and eucalyptus presence on litter dynamics of signal grass pasture (Urochloa decumbens $\mathrm{cv}$. Basilisk). The litter dynamics was studied in a silvipastoril system and in monoculture for 12 months. The experimental design was in randomized blocks with six replicates and five animals per paddock. The existing plant litter and the deposited ones were evaluated. The mean existing litter was 5,038 and 3,944 $\mathrm{kg} \mathrm{ha}^{-1}$ in the silvipastoril system and in monoculture, respectively. The silvipastoril system increased significantly the quantities of litter deposited. The quantity of nitrogen deposited in the pasture was greater in the silvipastoril system than in monoculture, 228 and $107 \mathrm{~kg} \mathrm{ha}^{-1}$ per year, respectively. The presence of legumes and the eucalyptus in the silvipastoril system provided nitrogen, shown by ${ }^{13} \mathrm{C}$ isotope analysis, and dry matter increases in the litter. Increases in the production of litter rich in nitrogen can contribute for the sustainability of signal pastures in a long run.
\end{abstract}

Index terms: Brachiaria decumbens, Urochloa decumbens, nitrogen fluxes, leguminous trees, tropical pasture.

\section{Introdução}

A introdução de gramíneas de origem africana, em especial o capim-gordura (Melinis minutiflora) e capim-colonião (Panicum maximum), no Bioma Mata-Atlântica, se confunde com a história da colonização do País. Por volta da década de 1970, essas gramíneas começaram a ser substituídas pelas braquiárias, espécies também africanas, mas de maior potencial de produção. Em poucos anos de uso, as pastagens formadas com braquiária - mais exigente em fertilidade do solo -, sob manejo inadequado, encontravam-se em processo de degradação. Uma das principais causas da perda de produtividade dessas pastagens é a baixa disponibilidade de nitrogênio (N) do solo, em razão da alta relação $\mathrm{C}: \mathrm{N}$ da serapilheira, depositada no solo pela braquiária (Boddey et al., 2003), e das altas taxas de lotação das pastagens (Boddey et al., 2004; Pereira et al., 2008). Myers \& Robbins (1991), Robbins et al. (1989) e Jantalia et al. (2006) atribuem à imobilização de $\mathrm{N}$ do solo, no processo de mineralização da serapilheira com alta relação $\mathrm{C}: \mathrm{N}$, a principal causa da degradação das pastagens.

A integração de pastagens com árvores, principalmente quando as espécies arbóreas são leguminosas, 
tem sido considerada uma opção viável para recuperar áreas degradadas (Carvalho et al., 2001). Por meio da deposição de biomassa, as árvores promovem aumentos da matéria orgânica e de outros nutrientes no solo (Xavier et al., 2003; Dias et al. 2006b). A deposição de biomassa das gramíneas e de árvores é um meio importante de reciclagem de nutrientes. A dinâmica de serapilheira em pastagens tropicais tem sido relatada em trabalhos recentes (Rezende et al., 1999; Cantarutti et al., 2002; Boddey et al., 2004). Nas pastagens estudadas por esses autores, os animais consumiram somente $30 \%$ da forragem disponível, assim, o retorno dos nutrientes, em especial $\mathrm{N}$, para o solo, via serapilheira, é maior que pelas fezes.

Espécies de leguminosas arbóreas que possuem a capacidade de fixar $\mathrm{N}_{2}$ apresentam geralmente maior potencial para adicionar nutrientes em sistemas de produção (Sierra \& Nygren, 2006; Macedo et al., 2008). As leguminosas arbóreas também propiciam condições favoráveis à fauna do solo, pela diminuição da relação $\mathrm{C}: \mathrm{N}$ de seus resíduos e, também, pelo efeito do sombreamento que estabelece um microclima mais favorável (Dias et al., 2006a).

Em um sistema silvipastoril, em que os componentes eram P. maximum e Leucaena leucocephala, foi relatado maior aumento na produção total de serapilheira (matéria seca e $\mathrm{N}$ total), em comparação à pastagem em monocultura (Sánchez et al., 2007). A produção anual de serapilheira foi de $12,49 \mathrm{Mg} \mathrm{ha}^{-1}$ por ano, em que L. leucocephala contribuiu com $72,8 \%$ deste total (Sánchez et al., 2007).

Este trabalho teve como objetivo avaliar o efeito, da introdução de leguminosas arbóreas e eucalipto em pastagens de braquiária na dinâmica da serapilheira.

\section{Material e Métodos}

O experimento foi realizado na Estação Experimental da Embrapa Gado de Leite, no Município de Coronel Pacheco, MG, a $21^{\circ} 33^{\prime} 22^{\prime \prime} \mathrm{S}$ e $43^{\circ} 06^{\prime} 15^{\prime \prime} \mathrm{W}$, à altitude de $426 \mathrm{~m}$. O clima da região é do tipo Cwa, clima tropical mesotérmico úmido, com verão quente e chuvoso (outubro a março) e inverno frio e seco (abril a setembro). A precipitação pluvial anual, média de 30 anos, é de $1.600 \mathrm{~mm}$, em que cerca de $90 \%$ ocorre de outubro a abril. A temperatura média anual é de $21,1^{\circ} \mathrm{C}$, com 23,7 e $18,5^{\circ} \mathrm{C}$, nos períodos chuvoso e seco, respectivamente.
Foi instalado um experimento em duas pastagens de braquiária (Urochloa decumbens cv. Basilisk), um em sistema silvipastoril (SSP) e outro em monocultura (MB). No sistema silvipastoril, as espécies arbóreas usadas foram: Acacia mangium, Mimosa artemisiana e Eucalyptus grandis. As duas primeiras espécies, que são leguminosas, foram utilizadas com a finalidade de fornecimento de sombra e biomassa rica em $\mathrm{N}$ e outros nutrientes, e a espécie E. grandis para a produção de madeira. As pastagens localizadas em área com declividade de $30-40 \%$ tinham cinco anos de idade e, antes de seu estabelecimento, encontravam-se em processo de degradação. As características químicas médias do solo, antes da implantação das pastagens, revelaram os seguintes valores: $\mathrm{pH}$ em água, 4,34; $\mathrm{H}+\mathrm{Al}, 6,44 \mathrm{cmol}_{\mathrm{c}}$ $\mathrm{dm}^{-3} ; \mathrm{Al}^{+3}, 0,33 \mathrm{cmol}_{\mathrm{c}} \mathrm{dm}^{-3} ; \mathrm{Ca}^{+2}, 0,19 \mathrm{cmol}_{\mathrm{c}} \mathrm{dm}^{-3} ; \mathrm{Mg}^{+2}$, $0,06 \mathrm{cmol}_{\mathrm{c}} \mathrm{dm}^{-3}$ e K $\mathrm{K}^{+}, 0,08 \mathrm{cmol}_{\mathrm{c}} \mathrm{dm}^{-3}$; $\mathrm{P}$ disponível (Mehlich), 2,12 $\mathrm{mg} \mathrm{kg}^{-1}$.

Por ocasião da implantação das pastagens (MB e SSP), foram feitas a calagem - com $1 \mathrm{Mg} \mathrm{ha}^{-1}$ de calcário dolomítico -, e a adubação com: $600 \mathrm{~kg} \mathrm{ha}^{-1} \mathrm{de}$ fosfato de Araxá, $250 \mathrm{~kg} \mathrm{ha}^{-1}$ de superfosfato simples, $100 \mathrm{~kg} \mathrm{ha}^{-1}$ de cloreto de potássio e $30 \mathrm{~kg} \mathrm{ha}^{-1} \mathrm{de}$ FTE BR-16. A adição do fosfato de Araxá foi feita em cobertura, com incorporação, por meio da gradagem, um mês antes do plantio. O calcário foi também incorporado, por meio da gradagem, 15 dias depois da aplicação do fosfato. O superfosfato simples e o cloreto de potássio foram aplicados em cobertura, por ocasião do plantio. A adubação para o plantio das mudas de A. mangium e $M$. artemisiana foi feita com aplicação de $50 \mathrm{~g}$ de calcário dolomítico, $80 \mathrm{~g}$ de fosfato de araxá, $100 \mathrm{~g}$ de superfosfato simples, $25 \mathrm{~g}$ de cloreto de potássio e $10 \mathrm{~g}$ de FTE BR-16, por cova e, para a espécie $E$. grandis, $75 \mathrm{~g}$ de sulfato de amônio, $225 \mathrm{~g}$ de superfosfato simples e $15 \mathrm{~g}$ de cloreto de potássio.

O plantio da braquiária foi realizado a lanço, em faixas preparadas em curva de nível. As espécies arbóreas foram plantadas em faixas de $10 \mathrm{~m}$ de largura, alternadas com faixas de pastagem de braquiária sem árvores, de $30 \mathrm{~m}$ de largura em cada hectare. Nas faixas de árvores, com quatro linhas, o espaçamento entre linhas foi de $3 \mathrm{~m}$. As espécies foram plantadas alternadamente nas linhas, com espaçamentos entre mudas de $3 \mathrm{~m}$. Inicialmente, o SSP contava com mais duas espécies de leguminosas: Acacia auriculiformis e Leucaena leucocephala. Assim, o SSP ficou com a 
densidade de 198 árvores por hectare (66 árvores de cada espécie).

Aos cinco anos de estabelecimento, foram coletadas informações durante o ciclo de um ano de pastejo (julho de 2005 a junho de 2006). O delineamento experimental adotado foi o de blocos ao acaso, com seis repetições. Foram utilizados cinco animais em cada tratamento (SSP e MB). O manejo adotado foi o de lotação intermitente, com período de ocupação do piquete $(0,5 \mathrm{ha})$ de sete dias e intervalo de desfolha de 35 dias, de forma que os animais permaneciam dentro do experimento, sem suplementação. Foram usadas novilhas mestiças (Holandês x Zebu) com idades entre oito e dez meses e com peso médio de $190 \mathrm{~kg}$.

No período de julho de 2005 a junho de 2006, foram determinadas as produções em 14 dias, da serapilheira existente e da depositada na pastagem, em MB e SSP. Considerou-se serapilheira todo material morto e solto da planta (gramínea e árvores) na superfície do solo. As técnicas e equações empregadas foram baseadas nos trabalhos de Bruce \& Ebersohn (1982) e no de Rezende et al. (1999).

Para a coleta da serapilheira existente $\left(\mathrm{SE}_{0}\right)$, foi utilizado um gabarito de $0,25 \mathrm{~m}^{2}$, lançado oito vezes ao acaso em cada repetição (piquetes). Das oito amostragens da serapilheira no SSP, quatro foram realizadas dentro das faixas e quatro nas extremidades das faixas de árvores, abaixo das copas. Para evitar a coleta de material trazido por pastejo ou pelo vento (contaminação), a serapilheira existente ao redor do gabarito foi descartada. Após 14 dias, retornava-se ao mesmo local, para recolher a serapilheira depositada $\left(\mathrm{SD}_{14}\right)$ na mesma área do gabarito em que a serapilheira existente fora coletada. O material coletado foi pesado após secagem em estufa a $65^{\circ} \mathrm{C}$ até peso constante. As amostras foram processadas para determinar o conteúdo de $\mathrm{N}$ e do ${ }^{13} \mathrm{C}$. Assim, mensalmente, esse processo era repetido.

Para o calculo do depósito da serapilheira, considerou-se a depositada em 14 dias $\left(\mathrm{SD}_{14}\right)$, em cada mês: $\mathrm{SD}_{\mathrm{M}}=\left(\mathrm{SD}_{14} / 14\right)$ x m (m é o número de dias em cada mês). O depósito anual foi obtido com a soma da serapilheira depositada mensalmente.

As taxas de desaparecimento da serapilheira foram avaliadas de acordo com Rezende et al. (1999). A constante de decomposição foi obtida com a equação: $\mathrm{k}=\left[\ln \left(\mathrm{SE}_{0}+\mathrm{SD}_{14}\right)-\ln \left(\mathrm{SE}_{14}\right)\right] / \mathrm{t}$ em que: $\mathrm{k}$ é a constante de decomposição da serapilheira; $\mathrm{SE}_{0}$ é o total de serapilheira existente no início da avaliação;
$\mathrm{SD}_{14}$ é o total de serapilheira depositada em 14 dias; $\mathrm{SE}_{14}$ é o total de serapilheira existente, na avaliação consecutiva à $\mathrm{SE}_{0}$; e t é o tempo entre as avaliações de serapilheira existente (14 dias).

Para o emprego desse modelo, assumiu-se que há um intervalo de tempo em que a serapilheira existente é constante. A constante de decomposição (k) foi expressa em termos de meia-vida da serapilheira, por meio da relação $\log _{\mathrm{e}}(2) / \mathrm{k}$.

A composição da serapilheira, proveniente de árvores $\left(\mathrm{C}_{3}\right)$ ou de braquiária $\left(\mathrm{C}_{4}\right)$, foi determinada com a análise da abundância natural de ${ }^{13} \mathrm{C}$ das amostras de serapilheira existente e depositada. Em SSP, das oito amostras de serapilheira existente e das oito de depositada em 14 dias, foram obtidas quatro amostras compostas. Em monocultura, foram analisadas duas das oito amostras, pois havia apenas gramíneas. As análises foram realizadas com o auxílio de espectrômetro de massas automatizado modelo Delta Plus (Finnigan MAT, Bremen, Alemanha) do laboratório da Embrapa Agrobiologia, conforme Cantarutti et al. (2002).

A percentagem de $\mathrm{C}$ proveniente das árvores contidas na serapilheira do SSP, foi obtida com o cálculo:

$\% \mathrm{C}_{\text {árvores }}=100\left(\delta{ }^{13} \mathrm{C}_{\text {serapilheira }}-\delta{ }^{13} \mathrm{C}_{\text {braq }}\right) /\left(\delta{ }^{13} \mathrm{C}_{\text {árvores }}-\delta\right.$ ${ }^{13} \mathrm{C}_{\text {braquiária }}$,

em que: $\delta{ }^{13} \mathrm{C}_{\text {serapilheira }}$ é a abundância natural de ${ }^{13} \mathrm{C}$ na serapilheira do SSP; $\delta{ }^{13} \mathrm{C}_{\text {braquíria }}$ é a abundância natural de ${ }^{13} \mathrm{C}$ na serapilheira da $\mathrm{MB}$, e o valor obtido e utilizado foi de $-13,90 \% ; \delta{ }^{13} C_{\text {árvores }}$ é a abundância natural de ${ }^{13} \mathrm{C}$ contido nas folhas de árvores (A. mangium, $M$. artemisiana e $E$. grandis), e o valor determinado e usado foi o de $-32 \%$.

Conforme foi feito para a produção de massa de matéria seca, os cálculos mensais e anuais da quantidade de $\mathrm{N}$ foram obtidos com os dados do conteúdo de $\mathrm{N}$ da serapilheira depositada em 14 dias. Também foram estimadas as taxas de liberação de $\mathrm{N}$ da serapilheira, com uso do conteúdo de $\mathrm{N}$ da serapilheira existente $\mathrm{e}$ depositada. O teor e a quantidade de $\mathrm{N}$ foram obtidos pelo método semimicro Kjeldahl com um destilador/ titulador automático Kjeltec.

Aanálise de variância considerou o modelo de parcela subdividida no tempo (Ramalho et al., 2000), em que os sistemas de pastagem (SSP e MB) foram considerados como parcelas, e os dados obtidos nos meses como subparcelas. Foi utilizado o programa computacional Sisvar (Ferreira, 2000). Para comparação das médias foi utilizado o teste de Tukey, a 5\% de probabilidade. 


\section{Resultados e Discussão}

Na serapilheira existente, a média anual foi maior na pastagem em SSP, porém não diferiu significativamente da média anual obtida na pastagem em MB (Tabela 1). Os dados médios anuais, obtidos na serapilheira depositada, apresentaram diferenças significativas entre as pastagens, com valores de 837 e de $623 \mathrm{~kg} \mathrm{ha}^{-1}$ por mês de massa de matéria seca (MS), em SSP e em $\mathrm{MB}$, respectivamente. A produção anual de serapilheira estimada foi de $21.811 \mathrm{e} \mathrm{de} 16.262 \mathrm{~kg} \mathrm{ha}^{-1}$ por ano de MS, em SSP e em MB, respectivamente. Em condições de Cerrado, Santos et al. (2006) estudaram três pastagens de braquiária em monocultura e relataram produções anuais de serapilheira entre 8.240 e $14.246 \mathrm{~kg} \mathrm{ha}^{-1}$ de MS, dependentes da espécie e da pressão de pastejo. No caso da espécie $U$. decumbens, com pressão de pastejo de $14 \%$, o valor foi de $14.246 \mathrm{~kg} \mathrm{ha}^{-1}$ de serapilheira, próximo ao encontrado na pastagem em MB, no presente trabalho. Anteriormente, Rezende et al. (1999) mencionaram que em pastagens de $U$. humidicola, no sul da Bahia, também em área de influência da Mata Atlântica, a quantidade de serapilheira depositada variou de 15 e $18 \mathrm{Mg} \mathrm{ha}^{-1}$ por ano de MS. Esses dois autores utilizaram a mesma metodologia do presente trabalho e consideraram, para o cálculo da produção de serapilheira anual, os valores obtidos em 14 dias.

A constante de decomposição da serapilheira (k) variou entre 0,0221 e $0,0238 \mathrm{~g} \mathrm{~g}^{-1}$ por dia, o que corresponde a meia-vida de 41 e 35 dias, quanto à pastagem em SSP e em MB, respectivamente. Esses valores não diferiram entre si (Tabela 1) e estão bem próximos aos citados na literatura. Em pastagens de $U$. humidicola, com e sem leguminosa herbácea, após correção, essas taxas variaram de 0,037 a $0,097 \mathrm{~g} \mathrm{~g}^{-1}$ por dia (Rezende et al., 1999).

Tabela 1. Médias anuais de serapilheira existente $\left(\mathrm{SE}_{0}\right)$ e depositada em 14 dias $\left(\mathrm{SD}_{14}\right)$, do total de serapilheira depositada em 12 meses $\left(\mathrm{SD}_{\text {total }}\right)$ e dos parâmetros constante de decomposição $(\mathrm{k})$ e meia-vida $\left(\mathrm{t} \frac{1}{2}\right)$, em pastagens de braquiária, em sistema silvipastoril (SSP) e em monocultura (MB) $)^{(1)}$.

\begin{tabular}{lccccc}
\hline Pastagem & $\begin{array}{c}\mathrm{SE}_{0} \\
\left(\mathrm{~g} \mathrm{~m}^{-2}\right)\end{array}$ & $\begin{array}{c}\mathrm{SD}_{14} \\
\left(\mathrm{~g} \mathrm{~m}^{-2}\right)\end{array}$ & $\begin{array}{c}\mathrm{SD}_{\text {total }} \\
\left(\mathrm{kg} \mathrm{ha}^{-1} \mathrm{ano}^{-1}\right)\end{array}$ & $\begin{array}{c}\mathrm{k} \\
\left(\mathrm{g} \mathrm{g}^{-1} \mathrm{dia}^{-1}\right)\end{array}$ & $\begin{array}{c}\mathrm{t} / 2 \\
(\mathrm{Dias})\end{array}$ \\
\hline SSP & $503,89 \mathrm{a}$ & $83,68 \mathrm{a}$ & $21.811 \mathrm{a}$ & $0,0222 \mathrm{a}$ & $41 \mathrm{a}$ \\
MB & $394,46 \mathrm{a}$ & $62,31 \mathrm{~b}$ & $16.262 \mathrm{~b}$ & $0,0238 \mathrm{a}$ & $35 \mathrm{a}$ \\
\hline
\end{tabular}

${ }^{(1)}$ Médias seguidas de letras iguais, nas colunas, não diferem entre si pelo teste F.
$\mathrm{O}$ teor e a quantidade de $\mathrm{N}$, na pastagem em $\mathrm{MB}$, apresentaram diferença significativa entre os meses avaliados, com médias de $0,66 \%$ e $0,41 \mathrm{~g} \mathrm{~m}^{-2}$, respectivamente. No SSP, a quantidade de $\mathrm{N}$ na serapilheira depositada foi maior nos meses de setembro e outubro, mas não diferiram significativamente dos outros meses, com exceção do mês de junho (Tabela 2).

As quantidades de $\mathrm{N}$ da serapilheira existente e da depositada foram significativamente maiores na pastagem em SSP (Tabela 3). As médias anuais da serapilheira existente e da depositada foram de $53 \mathrm{e}$ $8,8 \mathrm{~kg} \mathrm{ha}^{-1}$ de $\mathrm{N}$, respectivamente, na pastagem em SSP. Na pastagem em MB, os valores foram de 27 e de 4,1 $\mathrm{kg} \mathrm{ha}^{-1}$ de $\mathrm{N}$ na serapilheira existente e na depositada, respectivamente. Os totais da quantidade de $\mathrm{N}$ da serapilheira, depositado na pastagem em

Tabela 2. Teor e quantidade de $\mathrm{N}$ na serapilheira depositada em 14 dias, de julho de 2005 a junho de 2006, em pastagens de braquiária, em sistema silvipastoril (SSP) e em monocultura $(\mathrm{MB})^{(1)}$.

\begin{tabular}{|c|c|c|c|c|}
\hline \multirow[t]{2}{*}{ Mês } & \multicolumn{2}{|c|}{$\mathrm{N}(\%)$} & \multicolumn{2}{|c|}{ Quantidade de $\mathrm{N}\left(\mathrm{g} \mathrm{m}^{-2}\right)$} \\
\hline & SSP & $\mathrm{MB}$ & SSP & MB \\
\hline Julho & $1,01 \mathrm{aABC}$ & $0,62 \mathrm{bA}$ & $0,91 \mathrm{aAB}$ & $0,45 \mathrm{bA}$ \\
\hline Agosto & $1,03 \mathrm{aABC}$ & $0,67 \mathrm{bA}$ & $0,76 \mathrm{aAB}$ & $0,53 \mathrm{bA}$ \\
\hline Setembro & $0,98 \mathrm{aBC}$ & $0,62 \mathrm{bA}$ & $1,01 \mathrm{aA}$ & $0,49 \mathrm{bA}$ \\
\hline Outubro & $1,11 \mathrm{aAB}$ & $0,72 \mathrm{bA}$ & $0,99 \mathrm{aA}$ & $0,44 \mathrm{bA}$ \\
\hline Novembro & $1,10 \mathrm{aAB}$ & $0,66 \mathrm{bA}$ & $0,95 \mathrm{aAB}$ & $0,37 \mathrm{bA}$ \\
\hline Dezembro & $0,98 \mathrm{aBC}$ & $0,68 \mathrm{bA}$ & $0,94 \mathrm{aAB}$ & $0,52 \mathrm{bA}$ \\
\hline Janeiro & $0,88 \mathrm{aC}$ & $0,64 \mathrm{bA}$ & $0,76 \mathrm{aAB}$ & $0,32 \mathrm{bA}$ \\
\hline Fevereiro & $1,05 \mathrm{aAB}$ & $0,66 \mathrm{bA}$ & $0,95 \mathrm{aAB}$ & $0,38 \mathrm{bA}$ \\
\hline Março & $1,11 \mathrm{aAB}$ & $0,67 \mathrm{bA}$ & $0,88 \mathrm{aAB}$ & $0,40 \mathrm{bA}$ \\
\hline Abril & $1,10 \mathrm{aAB}$ & $0,65 \mathrm{bA}$ & $0,75 \mathrm{aAB}$ & $0,29 \mathrm{bA}$ \\
\hline Maio & $1,16 \mathrm{aA}$ & $0,66 \mathrm{bA}$ & $0,91 \mathrm{aAB}$ & $0,36 \mathrm{bA}$ \\
\hline Junho & $1,05 \mathrm{aAB}$ & $0,69 \mathrm{bA}$ & $0,68 \mathrm{aB}$ & $0,39 \mathrm{bA}$ \\
\hline
\end{tabular}

${ }^{(1)}$ Médias seguidas de letras iguais, minúsculas nas linhas e no mesmo parâmetro, não diferem entre si pelo teste $\mathrm{F}$; e médias seguidas de letras iguais, maiúsculas nas colunas, não diferem entre si, pelo teste de Tukey, a $5 \%$ de probabilidade.

Tabela 3. Médias anuais da quantidade de $\mathrm{N}$ da serapilheira existente $\left(\mathrm{SE}_{0}\right)$ e depositada em 14 dias $\left(\mathrm{SD}_{14}\right)$, do total de $\mathrm{N}$ da serapilheira depositada em 12 meses $\left(\mathrm{SD}_{\text {total }}\right)$ e dos parâmetros constante de decomposição $(\mathrm{k})$ e meia-vida $\left(\mathrm{t}^{1 / 2}\right)$, em pastagens de braquiária, em sistema silvipastoril (SSP) e em monocultura (MB) ${ }^{(1)}$.

\begin{tabular}{lccccc}
\hline Pastagem & $\begin{array}{c}\mathrm{SE}_{0} \\
\left(\mathrm{~g} \mathrm{~m}^{-2}\right)\end{array}$ & $\begin{array}{c}\mathrm{SD}_{14} \\
\left(\mathrm{~g} \mathrm{~m}^{-2}\right)\end{array}$ & $\begin{array}{c}\mathrm{SD}_{\text {total }} \\
\left(\mathrm{kg} \mathrm{ha}^{-1} \mathrm{ano}^{-1}\right)\end{array}$ & $\begin{array}{c}\mathrm{k} \\
\left(\mathrm{g} \mathrm{g}^{-1} \mathrm{dia}^{-1}\right)\end{array}$ & $\begin{array}{c}\mathrm{t}^{1 / 2} \\
(\mathrm{Dias})\end{array}$ \\
\hline SSP & $5,30 \mathrm{a}$ & $0,88 \mathrm{a}$ & $228 \mathrm{a}$ & $0,0224 \mathrm{a}$ & $46 \mathrm{a}$ \\
MB & $2,68 \mathrm{~b}$ & $0,41 \mathrm{~b}$ & $107 \mathrm{~b}$ & $0,0298 \mathrm{a}$ & $42 \mathrm{a}$ \\
\hline
\end{tabular}

${ }^{(1)}$ Médias seguidas de letras iguais, nas colunas, não diferem entre si pelo teste F. 
SSP e em MB, foram 228 e $107 \mathrm{~kg} \mathrm{ha}^{-1}$ por ano, respectivamente.

A constante $\mathrm{k}$ de decomposição da serapilheira calculada variou de 0,0224 a $0,0298 \mathrm{~g} \mathrm{~g}^{-1}$ por dia, para as pastagens em SSP e em MB, respectivamente. A taxa de liberação do $\mathrm{N}$ expresso em termos de meia-vida da serapilheira, obtido na pastagem em SSP, foi de 46 dias e não diferiu significativamente do valor de 42 dias obtido em MB (Tabela 3).

A presença de folhas de árvores (A. mangium, $M$. artemisiana e $E$. grandis) aumentou a quantidade de $\mathrm{N}$ na serapilheira depositada, mas não alterou o tempo de decomposição do resíduo da pastagem. Apesar de as leguminosas contribuírem para aumentar o aporte de $\mathrm{N}$ na serapilheira e, consequentemente, a mineralização deste nutriente (Balieiro et al., 2004), a presença das folhas de E. grandis, que contêm substâncias recalcitrantes (Aprile et al., 1999), provavelmente limitou o efeito benéfico das leguminosas.

Em sistemas de pastagens de $U$. decumbens e $U$. brizantha, formadas em solos de baixa fertilidade natural, Carvalho et al. (2001) verificaram que a ocorrência de diversas espécies arbóreas, em que a maioria era de leguminosas, resultou em aumentos na quantidade de $\mathrm{N}$ nas folhas verdes das gramíneas e na serapilheira, nas áreas de influência das árvores.

Os resultados da análise isotópica de ${ }^{13} \mathrm{C}$ confirmaram que a serapilheira do SSP era composta de árvores e gramíneas (Tabela 4). As amostras avaliadas apresentaram valores característicos de plantas $\mathrm{C}_{3}$ que compõem o sistema: A. mangium, M. artemisiana

Tabela 4. Valores de $\delta 13 \mathrm{C}$ na serapilheira depositada em 14 dias (SD14) e na serapilheira existente (SE0), de julho de 2005 a junho de 2006, em pastagem de braquiária em sistema silvipastoril.

\begin{tabular}{lcc}
\hline Mês & $\mathrm{SD}_{14}$ & $\mathrm{SE}_{0}$ \\
\hline Julho & $-21,12 \pm 0,92$ & $-22,12 \pm 0,52$ \\
Agosto & $-26,85 \pm 0,26$ & $-22,02 \pm 0,91$ \\
Setembro & $-25,06 \pm 0,55$ & $-21,76 \pm 0,68$ \\
Outubro & $-25,98 \pm 1,26$ & $-23,23 \pm 0,54$ \\
Novembro & $-27,10 \pm 0,69$ & $-22,11 \pm 0,38$ \\
Dezembro & $-25,86 \pm 0,99$ & $-23,40 \pm 0,91$ \\
Janeiro & $-25,77 \pm 1,01$ & $-21,92 \pm 0,63$ \\
Fevereiro & $-25,53 \pm 0,43$ & $-21,54 \pm 0,39$ \\
Março & $-27,04 \pm 0,46$ & $-23,22 \pm 0,56$ \\
Abril & $-27,53 \pm 0,96$ & $-22,91 \pm 0,99$ \\
Maio & $-27,77 \pm 0,26$ & $-22,55 \pm 0,55$ \\
Junho & $-27,07 \pm 0,50$ & $-22,11 \pm 0,57$ \\
\hline
\end{tabular}

e E. grandis. Plantas do ciclo $\mathrm{C}_{3}$ discriminam mais intensamente $\mathrm{o}{ }^{13} \mathrm{C}$ e apresentam variações na abundância isotópica de ${ }^{13} \mathrm{C}$ de -20 a $-34 \delta$ (Urquiaga et al., 2006).

$\mathrm{O}$ valor de ${ }^{13} \mathrm{C}$ obtido na serapilheira em $\mathrm{MB}$, foi em média $-13,90 \%$. Os valores de $\delta{ }^{13} \mathrm{C}$ foram compatíveis com os citados sobre gramíneas $\mathrm{C}_{4}$, no trabalho de Cantarutti et al. (2002). As plantas de ciclo $\mathrm{C}_{4}$ discriminam menos o ${ }^{13} \mathrm{C}$, com valores que variam de -9 a $-17 \delta$ (Urquiaga et al., 2006).

\section{Conclusões}

1. A presença de árvores promove o aumento de deposição de serapilheira, em pastagem de Urochloa decumbens.

2. A taxa de decomposição da serapilheira, em pastagem de $U$. decumbens em monocultivo ou em consórcio com as espécies Acacia mangium, Mimosa artemisiana e Eucalyptus grandis não difere.

3. Incrementos na produção de serapilheira rica em nitrogênio, no sistema silvipastoril, podem, a longo prazo, contribuir para a sustentabilidade das pastagens de braquiária.

\section{Referências}

APRILE, F.M.; DELITTI, W.B.C.; BIANCHINI JUNIOR, I. Aspectos cinéticos da degradação de laminados de madeira em ambientes aquático e terrestre. Revista Brasileira de Biologia, v.59, p.485-492, 1999.

BALIEIRO, F. de C.; FRANCO, A.A.; PEREIRA, M.G.; CAMPELLO, E.F.C.; DIAS, L.E.; FARIA, S.M.; ALVES, B.J.R. Dinâmica da serapilheira e transferência de nitrogênio ao solo, em plantios de Pseudosamanea guachapele e Eucalyptus grandis. Pesquisa Agropecuária Brasileira, v.39, p.597-601, 2004.

BODDEY, R.M.; MACEDO, R.; TARRE, R.M.; FERREIRA, E.; OLIVEIRA, O.C.; REZENDE, C.D.; CANTARUTTI, R.B.; PEREIRA, J.M.; ALVES, B.J.R.; URQUIAGA, S. Nitrogen cycling in Brachiaria pastures: the key to understanding the process of pasture decline. Agriculture Ecosystems and Environment, v.103, p.389-403, 2004.

BODDEY, R.M.; XAVIER, D.F.; ALVES, B.J.R.; URQUIAGA, S. Brazilian agriculture: the transition to sustainability. Journal of Crop Production, v.9, p.593-621, 2003.

BRUCE, R.C.; EBERSOHN, J.P. Litter measurements in two grazed pastures in south east Queensland. Tropical Grasslands, v.16, p.180-185, 1982.

CANTARUTTI, R.B.; TARRÉ, R.M.; MACEDO, R.; CADISCH, G.; REZENDE, C. de P.; PEREIRA, J.M.; BRAGA, J.M.; GOMIDE, J.A.; FERREIRA, E.; ALVES, B.J.R.; URQUIAGA, S.; 
BODDEY, R.M. The effect of grazing intensity and the presence of a forage legume on nitrogen dynamics in Brachiaria pastures in the Atlantic Forest region of the south of Bahia, Brazil. Nutrient Cycling in Agroecosystems, v.64, p.257-271, 2002.

CARVALHO, M.M.; XAVIER, D.F.; ALVIM, M.J. Uso de leguminosas arbóreas na recuperação e sustentabilidade de pastagens cultivadas. In: CARVALHO, M.M.; ALVIM, M.J.; CARNEIRO, J. da C. (Ed.). Sistemas agroflorestais pecuários: opções de sustentabilidade para áreas tropicais e subtropicais. Juiz de Fora: Embrapa Gado de Leite; Brasília: FAO, 2001. p.189-204.

DIAS, P.F.; SOUTO, S.M.; CORREIA, M.E.F.; ROCHA, G.P.; MOREIRA, J.F.; RODRIGUES, K. de K.; FRANCO, A.A. Árvores fixadoras de nitrogênio e macrofauna do solo em pastagem de híbrido de Digitaria. Pesquisa Agropecuária Brasileira, v.41, p.1015-1021, 2006a.

DIAS, P.F.; SOUTO, S.M.; RESENDE, A.S. de; MOREIRA, J.F.; POLIDORO, J.C.; CAMPELL, E.F.; FRANCO, A.A. Influência da projeção das copas de espécies de leguminosas arbóreas nas características químicas do solo. Pasturas Tropicales, v.28, p.8-17. 2006b.

FERREIRA, D.F. Sistemas de análise estatística para dados balanceados. Lavras: Ufla, 2000. 145p.

JANTALIA, C.P.; TÁRRE, R.M.; MACEDO, R.O.; ALVES, B.J.R.; URQUIAGA, S.; BODDEY, R.M. Acumulação de carbono no solo em pastagens de Brachiaria. In: ALVES, B.J.R.; URQUIAGA, S.; AITA, C.; BODDEY, R.M.; JANTALIA, C.P.; CAMARGO, F.A.O. (Ed.). Manejo de sistemas agrícolas: impactos no seqüestro de $\mathrm{C}$ e nas emissões de gases de efeito estufa. Porto Alegre: Gênesis, 2006. p.157-170.

MACEDO, M.O.; RESENDE, A.S.; GARCIA, P.C.; BODDEY, R.M.; JANTALIA, C.P.; URQUIAGA, S.; CAMPELLO, E.F.C.; FRANCO, A.A. Changes in soil $\mathrm{C}$ and $\mathrm{N}$ stocks and nutrient dynamics 13 years after recovery of degraded land using leguminous nitrogen-fixing trees. Forest Ecology and Management, v.255, p.1516-1524, 2008.

MYERS, P.K.R.; ROBBINS, G.B. Sustaining productive pastures in the tropics. 5. Maintaining productive sown grass pastures. Tropical Grasslands, v.25, p.104-110, 1991.

PEREIRA, J.M.; TARRÉ, R.M.; MACEDO, R.; REZENDE, C. de P.; ALVES, B.J.R.; URQUIAGA, S.; BODDEY, R.M. Productivity of Brachiaria humidicola pastures in the Atlantic Forest region of Brazil as affected by stocking rate and the presence of a forage legume. Nutrient Cycling in Agroecosystems, v.83, p.179-196, 2008.

RAMALHO, M.A.P.; FERREIRA, D.F.; OLIVEIRA, A.C. de. Experimentação em genética e melhoramento de plantas. Lavras: UFLA, 2000. 326p.

REZENDE, C. de P.; CANTARUTTI, R.B.; BRAGA, J.M.; GOMIDE, J.A.; PEREIRA, J.M.; FERREIRA, E.; TARRÉ, R.M.; MACEDO, R.; ALVES, B.J.R.; URQUIAGA, S.; CADISCH, G.; GILLER, K.E.; BODDEY, R.M. Litter deposition and disappearance in Brachiaria pastures in the Atlantic Forest region of the south of Bahia, Brazil. Nutrient Cycling in Agroecosystems, v.54, p.99-112, 1999

ROBBINS, G.B.; BUSHELL, J.J.; MCKEON, G.M. Nitrogen immobilization in decomposing litter contributes to productivity decline in ageing pastures of green panic (Panicum maximum var. trichoglume). Journal of Agricultural Science, v.113, p.401-406, 1989.

SÁNCHEZ, S.; CRESPO, G.; HERNÁNDEZ, M. Acumulación de hojarasca en un pastizal de Panicum maximum y Leucaena leucocephala. Pastos y Forrajes, v.30, p.357-371, 2007.

SANTOS, R.S.M.; ALVES, B.J.R.; URQUIAGA, S.; BODDEY, R.M. Avaliação da produtividade primária aérea líquida de três espécies de Brachiaria sob diferentes taxas de lotação animal. In: ALVES, B.J.R.; URQUIAGA, S.; AITA, C.; BODDEY, R.M.; JANTALIA, C.P.; CAMARGO, F.A.O. (Ed.). Manejo de sistemas agrícolas: impactos no sequestro de $\mathrm{C}$ e nas emissões de gases de efeito estufa. Porto Alegre: Genesis, 2006. p.133-156.

SIERRA, J.; NYGREN, P. Transfer of $\mathrm{N}$ fixed by a legume tree to the associated grass in a tropical silvopastoral system. Soil Biology \& Biochemistry, v.38, p.1893-1903, 2006.

URQUIAGA, S.; ALVES, B.J.R.; CAMPOS, D.V.; BODDEY, R.M. Aplicação de técnicas de ${ }^{13} \mathrm{C}$ em estudos de seqüestro de $\mathrm{C}$ em solos agrícolas. In: ALVES, B.J.R.; URQUIAGA, S.; AITA, C.; BODDEY, R.M.; JANTALIA, C.P.; CAMARGO, F.A.O. (Ed.). Manejo de sistemas agrícolas: impactos no seqüestro de $C$ e nas emissões de gases de efeito estufa. Porto Alegre: Genesis, 2006. p.13-33.

XAVIER, D.F.; CARVALHO, M.M.; ALVIM, M.J.; BOTREL, M.A. Melhoramento da fertilidade do solo em pastagem de Brachiaria decumbens associada com leguminosas arbóreas. Pasturas Tropicales, v.25, p.21-26, 2003.

$\overline{\text { Recebido em } 29 \text { de junho de } 2010 \text { e aprovado em 1ㅇ de agosto de } 2011}$ 